\title{
Managing the quality and completeness of customer data
}

Received (in revised form): 21st November, 2002

\section{Bryan Foss}

is IBM's global lead for customercentricity and risk management solutions for retail banks and associated financial services companies.

\section{lain Henderson}

is an associate of $\mathrm{QCi}$, specialising in sourcing, management and use of customer information.

\section{Peter Johnson}

is an IT architect within the IBM customer intelligence practice, specialising in data movement and data improvement.

\section{Don Murray}

is an independent consultant with 18 years' experience in the design of very large customer databases.

\section{Merlin Stone}

is IBM Professor of Business Transformation at Surrey University, IBM's Business Research Leader and Director of QCi, Charter UK, The Database Group and ViewsCast.

\begin{abstract}
Although companies have been collecting customer-related data for years, this was normally for administration rather than customer management. While larger companies have more recently collected customer data for database marketing (to recruit new customers, sell more to existing customers, support customer service operations and retain customers), returns are usually limited because most data are still held and used departmentally. The growth of contact centres, e-commerce and more complex value chains has raised additional issues of enterprise data management and exploitation, while demonstrating beyond doubt that available data are insufficient to support new customer management processes. This paper considers these issues and proposes tried and tested approaches for addressing these customer data management issues in a practical and achievable manner.
\end{abstract}

Bryan Foss

IBM Retail Banking Solutions, Financial Services Sector, Global Team, IBM UK Ltd, 17 Addiscombe Road, Croydon CR9 6HS, UK.

Tel: $+44(0) 2086814402$ Fax: +44 (0)20 8681 4402; e-mail:

bryan_foss@uk.ibm.com

\section{Why data quality has become a big issue in managing customers}

In many companies, customer data were originally collected and managed departmentally - and in some they still are. Companies have been collecting customer data for years, usually for customer administration. In the 1980s, some larger companies started to collect more customer data and use them for what was then called database marketing
- to recruit new customers, sell more to existing customers, support customer service operations and retain customers. This meant bringing data from various systems together, adding new and relevant customer data. These data are typically sourced from several operational or product systems, as well as from marketing, sales and service systems. So interdepartmental systems evolved, with interfaces between them. The last few 
years have seen the growth of electronic commerce, with data involving customers being exchanged online between different companies within value chains and between companies and customers. Inter-enterprise customer management is an area being explored, stimulated by the idea of combining customer relationship management (CRM) and enterprise resource planning (ERP) into enterprise customer relationship management (ECRM).

In theory, in the process of customer management, customer data should be provided to various participants (including the customer), at the right time in the right format. Many businesses, however, have problems with the quality and 'fitness for purpose' of their customer data. Over time it has become incomplete, or been unnecessarily duplicated. It may also have been collected from and re-dispersed into various geographies, business units and locations, leading to inconsistencies in use and definition. Many businesses now need to move faster than they once did (eg to identify which customers might be affected by a new campaign from a competitor), so data often need to be accessed and analysed faster. One result of these pressures is that companies seek the 'best quality' information from many similar data items. Though a single physical source of information may seem desirable, it may be hard, even impossible, to achieve. A company needs, however, to know the state of its data so it can decide what needs improving, where and what sorts of benefit it will get. By investigating data quality a company can decide when and where to put its effort.

In this paper, the authors investigate some trends in the use of customer data, some problems involved in managing large customer data sets, and some solutions to these problems. In particular, they cover:
- the requirement for successful customer data planning

- the main activities involved in customer data planning

- how to handle problems of integration and movement as the plan is implemented.

\section{TRENDS IN THE USE AND MANAGEMENT OF CUSTOMER DATA}

The main trends in the use of customer data are summarised below.

Transaction and case management: data are being used in ever-increasing volumes to manage more and more transactions, often in greater detail. Simple purchases become cases to be managed, with much deeper data about customers being collected, stored and used to understand behaviours and trends.

Risk and resilience: a series of events, from terrorist attacks, corporate fraud and general commercial risks (some enhanced by increasing remoteness of companies from customers) has caused attention to be focused on the risks of poor quality data management and exposure to manipulation. In some cases this is due to risk management requirements, global and local regulatory requirements or national security requirements.

Trust and identity: a conflict exists between the needs of data completeness, the security of customer-facing systems and the trust and privacy requirements of customers. To assist authentication and appropriate customer management, users must give information. This is no different to the way things work in the non-digital world, but the questioning seems more invasive or suspicious when the user knows that these data are being stored for future use. The debate about the relationship between data, privacy and trust has implications for many other 
areas such as access control, the construction and use of public or private directories, identity management, including avoidance of identity theft, and use of biometrics. 'Digital identity' may be the 'next big thing' in the evolution of eCRM. The component parts include single sign-on technologies and processes, 'trusted computing' (next generation hardware/software), authentication (biometrics etc), network identity management (Verisign etc).

Multi-channel customer management: customers are often managed over several direct channels and through intermediaries, with the requirement that data collected in each channel are checked for consistency with that available in other channels, often in real time or at least near real time.

Spread of customer data across the organisation: customer data were once used by only one or two functions or departments (eg customer administration and customer service). It is now used by and of interest to many different functions or departments, often working to different timetables and priorities but requiring the same data for different but associated purposes (eg marketing, customer value, risk and financial management). They have a tendency to set up their own databases, and certainly to work to different standards.

Merging of the business and the individual as data sources: it was conventional to distinguish between businesses and individual consumers. In most markets, however, data about the small business relate to an individual (who may consume the product or service too, eg in telephony or financial services). Data about businesses and about consumers are, however, often gathered and managed separately. In some countries, data protection or privacy laws require the same (high) standards of data management to be observed for business and consumer individuals.

Customer desire to manage supplier, not vice versa: as call centres and e-channels have developed, some customers have shown their desire to manage their transactions and relationships with their suppliers.

Proliferation of data storage: many companies have tried to centralise storage of customer data, but the proliferation of storage devices has allowed company staff to create their own customer view. The best example of this is a sales force. This tendency has been exacerbated by CRM system suppliers' exaggerated claims about the ease of integrating these distributed data stores with the main customer database, such that users suffer no performance reduction. In many cases, the customer also manages part of the data storage, on a smart card or similar device.

Insourcing and outsourcing: customer data are proving hard for many companies, especially larger ones, to manage, so some are turning to business partners to manage the data for them 'until the situation stabilises'. This, however, may never happen. Thus, in-house CRM systems are proving so hard for large companies to manage that some are turning to Applications Service Provision models, leaving the data problems to suppliers who specialise in the area. An alternative model is to set up a separate internal division which behaves like an external supplier (insourcing).

Conflict between operational access and quality: in most companies, a prime requirement is that some elements of customer data be available at the highest quality levels for operational access. This can lead to problems with the performance of customer database systems unless good systems work is done to identify the different applications and design storage and access systems that work together to meet the needs of different types of user. 


\section{DATA INTERPRETATION}

A major factor influencing the quality of data is perception. Over time, if an assumption remains unchecked, it starts to become 'the truth' whether or not it has an objective or factual basis, from both business and technical perspectives. To verify a common technical understanding may involve investigation into hardware platforms, middleware, application programming languages used, natural languages used by operating systems, and the presentation of data through terminal emulation software. A business view is needed to determine consistency of meaning and common language used. The incidences of homonyms and synonyms must be understood, and any terms or jargon categorised as local, regional or global. This may be achieved through reference to a common industry (or single company) process and data model.

Some data problems are said to be due to the complexity of customer data held on operational or legacy systems used to manage customers (where a legacy system has sometimes been described as 'a system that has achieved production status'). This may indicate lack of understanding of these systems due to poorly updated documentation, lack of original staff or reduced maintenance. If, however, these systems were restructured or the data mapped from these sources into, say, a relational data format, the data structures derived would be much simpler to navigate than those of today's sophisticated and complex packages. This current breed of packages are designed to be tailored through configuration and so include functionality redundant to some companies. They tend to use proprietary data structures to aid local performance and do not open themselves easily to investigation or interfaces with other systems that require or provide the same data. Specialist consultancy skills are usually needed to customise these packages and to investigate how links between packages can be created in a rapid and low-risk manner.

\section{THE DETERMINANTS OF DATA QUALITY}

The main components of customer data quality, in its widest sense, are described below.

\section{Completeness}

Completeness is the proportion of all possible relevant data sources and the coverage across all defined data fields that a company has integrated into its decision support and operational CRM processes. If there are data about customers in many different operational data stores, then all relevant data sources should be integrated into the CRM and informational systems in order to deliver data for customer insight and operational customer management use. This also refers to sources of outside customer data (commercially supplied or from business partners).

\section{Appropriateness}

Appropriateness measures how far data match the business purposes for which they are collected and used. This can be interpreted statically or dynamically. Static appropriateness refers to how well the data represent the customers - who they are, what they buy and their reasons for doing so. Dynamic appropriateness refers to ability to cope with the future - whether tactically (ie do the data help predict what customers want and when to apply these offers), or strategically (ie will they support the strategic direction of the company in terms of marketing new products and services, customer segmentation and the development of 
appropriate propositions, use of new channels of distribution etc.

\section{Accuracy}

Accuracy is the overall accuracy of the data associated with each customer record. Once a company has all the sources and fields identified and populated, how accurate is data content? In most companies this answer varies with source. Accuracy has often to be judged against meta-data definitions. A substantial case study (GreatRisk Insurance - anon) is available from IBM on this topic, demonstrating that a substantial proportion of customer-related data is far below the accuracy required for customer management purposes.

\section{Grouping accuracy}

Grouping is the accuracy with which a company can consolidate and match data from disparate sources. Once a company has identified all data sources and ensured that they are accurate and representative of the same time period, how well can the company identify and group multiple occurrences of the same customer in order to provide a comprehensive accurate customer portrait? These data may include many transactions and contacts which take place without sufficient consistency of unique customer recognition.

\section{Access}

Access is the speed and accuracy with which a company can integrate its data and provide them in a usable form across all decision support and customer-facing applications, ie delivering the right data to the right person at the right time in the right format. Some customer management activities (eg successful and profitable retention) can rely on quite small items of data being available to assist in rapid and appropriate decision making during customer contact. A customer management data assessment can help identify the core data items that are required to underpin such processes.

\section{Confidence}

An organisation and users of data must be confident that the achieved quality of data is 'business as usual' and not the result of a special effort. It is the experience and knowledge (or ignorance) of data users that sets their confidence levels and affects their effectiveness in using the data. New users often give data sources their own 'sanity check' using alternative reference points and reports. Confidence can be quickly undermined, causing the data not to be relied on if these simple checks fail. A more formal and automated data audit process can produce statistical metrics that demonstrate the quality of the data and provide the required confidence to ensure that new systems are more fully utilised and exploited.

\section{Currency}

Currency refers to how old data are, ie when they were last captured or verified through checking or use. Systems are designed to try and capture or emulate reality, so the value they bring is relative to the frequency with which their data are validated or updated.

\section{Regulatory and legal compliance}

In most countries, there are laws or regulations stating how customer data should be processed (collected, stored, used, changed, made accessible to customers and disposed of). These relate to areas such as privacy, data protection, 
national security, safety, human rights or competition. Specific laws and regulations apply to certain sectors, eg financial services, utilities, telecommunications, automotive and government. In financial services, the reasons for this include credit vetting, protection against insurance fraud and anti-money laundering. For utilities they are to prevent against abuse of monopoly. For telecommunications they meet the need for privacy, as well as monopoly abuse. For the automotive sector the requirement is a safety one (eg for product recall). For government the issue is one of powers - the statutes put in place to establish boundaries around what departments may or may not do (in this case share certain types of data for any use beyond fraud prevention). Regulation is often complemented by documented or agreed practices in or across industries or geographies (eg The Banking Code of Conduct). Compliance with these requirements in all processing of customer data is becoming a critical attribute of data quality, customer confidence and reputation.

\section{Meta-linking}

Meta-linking refers to how meta-data representing different data variables are combined to represent higher-level variables. Here are some simple business examples of derived or linked data. The wealth of two or more individual members of a family might be construed to be family wealth. A trip one-way between two destinations followed by a return trip the same day can be construed as a day return trip. Several purchases made in a store but at different tills within two hours might be construed as a shopping trip. Meta-data are central to the interpretation of data and reality. A properly meta-linked data set has important groupings identified and represented by meta-variables that are of business value in customer management.

\section{THE NEED FOR CUSTOMER INFORMATION PLANNING}

The effective management and integration of a wide range of customer data are central to success of most customer management projects. Yet, according to research into why CRM projects fail, the number one reason for failure was that the customer data were being ignored. ${ }^{1}$ Good customer management requires good customer data management. Thus, out of the 260 best customer management practices identified in QCi's Customer Management Assessment Tool (CMAT), 140 require good management and use of customer information. ${ }^{2}$ Most enterprises still undertake CRM with no practical idea of what they hope to build in the long term. One solution is haphazardly joined with another, initiatives and executives come and go, and soon enthusiasm wanes. Senior managers need to understand data management if they are to get best value from customer data in the short term and over time. In the authors' view, a comprehensive customer information plan is a central component of any customer management change programme, and essential if senior managers are to really understand how customer data quality underpins their efforts to improve customer management.

\section{WHAT SHOULD A CUSTOMER INFORMATION PLAN CONTAIN?}

\section{Vision and strategy}

This is the 'big picture' view of what customer information can do for the organisation when it is fully aligned with, and is informing, business objectives. This includes a review of the 
opportunities and threats arising from customer information, including the potential for markets to be intermediated by others who hold strong data assets; the deployment of robust 'privacy' policies; the understanding of the opt-in/opt-out debate; and opportunities for value-chain partnering to access customer or prospect data. It also includes an understanding of what external data are available (or likely to become available) in each geography and the norms for collection and internal use of customer data.

\section{Investment}

This ensures that investments in customer data are made in the right areas and in a prioritised and coordinated way, to get the best results and returns on investment while managing data-related risks. It includes how the organisation defines and measures the value of customer information, and how it develops a culture that manages data and maximises this value. It also covers options for design and implementation of data management processes and capabilities.

\section{Resources}

This relates to whether the right resources are being assembled and deployed, what types and numbers of functional specialists are required, and how the resources will be developed and grown over time in line with business needs. Customer information touches the day-to-day roles of many staff. This brings in issues of training (in capturing and managing customer data and in using technology to do it) and of the process of managing/using customer information (with accompanying incentives or sanctions). Issues of privacy arise - the more staff, channels or partners that use customer data, the greater the risk.
Security is an issue, with most breaches due to human rather than systems error. The ever-increasing use of information causes problems in previously unrelated areas - eg branding and reputation. Years of brand development work can be undone by a weak privacy policy, or inappropriate or invasive use of information in a sensitive area.

\section{Customer data assembly and evaluation}

This requires an overview of what information is and should be available to end users, its quality and whether there are 'crown jewels' or hidden assets to be developed and protected. This should include volumetrics on data available by type, including number of customer/ prospect records, transactional and descriptive data available and any attitudinal or needs data, including overlays derived from market research and external data sources. This in turn requires definition of the type of data to be collected, derived, managed and exploited (see Figure 1).

\section{Information usage}

This requires an overview of how information is made available to relevant users in a timely manner and how each function is using it or plans to use it. It includes input from marketing, sales, customer service, finance (including fraud detection and risk management) and operations. It also includes a breakdown of application software used in each function.

\section{Information management}

This covers detail on how customer data are managed as an asset of the business. It builds on understanding of how the organisation invests in customer data. It 
Foss et al.

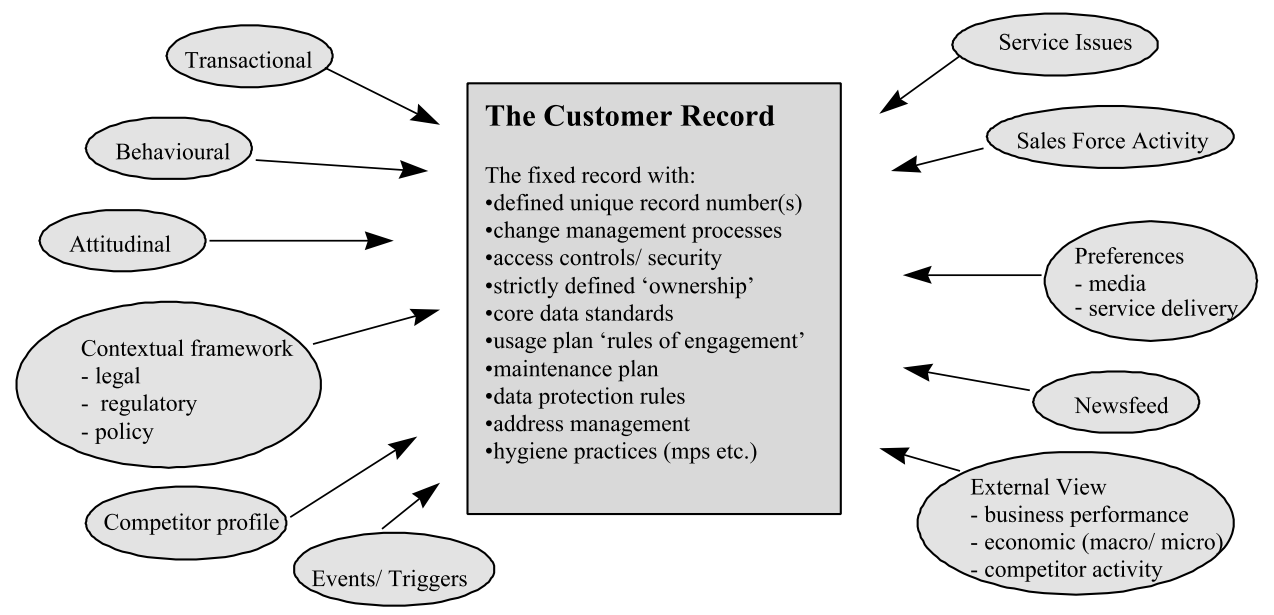

Figure 1: Data types

includes detail on data availability by type, refresh rates and frequency of updates or validation. It gives an overview of the data model/data architecture that supports customer systems and how closely it supports a 'single view of the customer'. It also covers how the IT function meets legal requirements, eg privacy laws, and an overview of current and planned information security measures.

\section{Technology support}

This covers how technology supports information management and usage now and in the future. It includes provision of access to data in line with the needs of different users (including customers themselves), and the varied technology requirements of large scale data gathering, storage, management, movement and usage.

It has been suggested that the sales and marketing budgets of software and technology providers are linked to the CRM bubble. Implementations focused on software and technology have suffered from overconcentration on those areas to the detriment of other critical CM project success factors (eg people, data, processes, business and systems integration). Many organisations focused on the customer interface, itself obviously of benefit, but the benefits would have been greater if the customer data infrastructure had been considered and addressed in advance, allowing the development and integration of strong analysis and planning capabilities with customer interaction. Typically this means the establishment of a single customer, product, channel and risk database for CM analysis and planning (or at least having a single view derived from other systems). This new form of data warehouse requires detailed industry-specific data models, defined data interfaces and data quality improvement programmes. A similar real-time or operational customer database supports customer interaction with appropriate and timely decision data. Unless an organisation has only one customer-facing application (unlikely), its operational customer database should sit outside the applications in a central channel and application-independent repository. To have it tied in too closely to (or within) an application (eg single CRM channel) means that it will work well with that application, but is unlikely to be structured so as to enable similar strong working with others, limiting the ability 


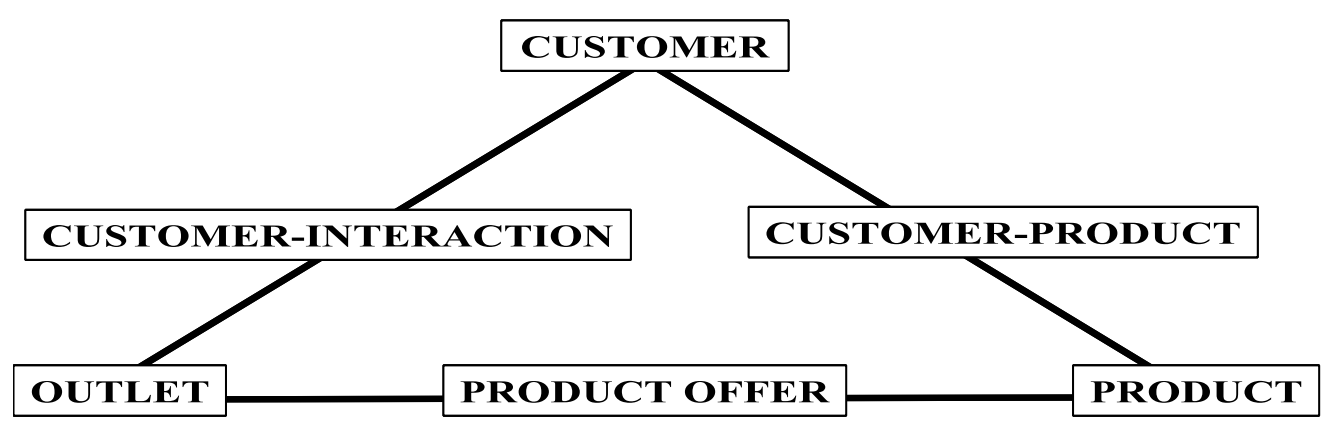

Figure 2: The main components of a customer and product database

to manage customers consistently across channels with common marketing and sales processes.

\section{Integration}

This relates to ensuring that information management and usage work well as an integrated set of activities, including whether the many and varied requirements of customer data management are supported by an integrated set of processes, activities, functional groups, project plans and investment cases. Typically 'integration' in the context of customer data is interpreted in terms of technology, ie integrated systems, interfaces and flows of customer information. It should be wider than this. The system needs to work in an integrated manner. Senior management need to ensure that functional teams work together, informing each other of significant issues, dependencies, developments and investments for the overall good. This is one area where CRM has helped - at the start of many CRM programmes the main customer-facing functional groups (sales, marketing and customer service) are involved (although this needs to be extended to finance, risk management and operations). This integration, however, often breaks down somewhere in the planning or programme execution. For example, many CRM programmes focus on reducing customer service costs, but in practice they increase customer exit rates and acquisition costs and reduce cross-selling opportunities.

\section{Data architecture}

An analytical database supporting customer management should focus on who bought what from where, to predict, or better still affect (through proposition development and appropriate timing) the next purchase. The who/what/where of customer management are the customer, the product or service and the outlet. These are shown in Figure 2 as the three axes of the triangle. The boxes can represent tables of information held in a relational database although alternative relational structures can equally be applied. The customer table will usually contain current and lapsed customers as well as prospects and even suspects, ie potential future customers. The product will vary according to the industry involved. The outlet could be a branch or a store, a contact centre or kiosk, a catalogue on printed paper or in an electronic medium, a web page or an advertisement. It is more than just a channel - it is the precise location of any offer of a product or service.

These three areas are linked by three further tables, or sets of tables. The customer-product tables hold details of all relationships between the customer 
Foss et al.

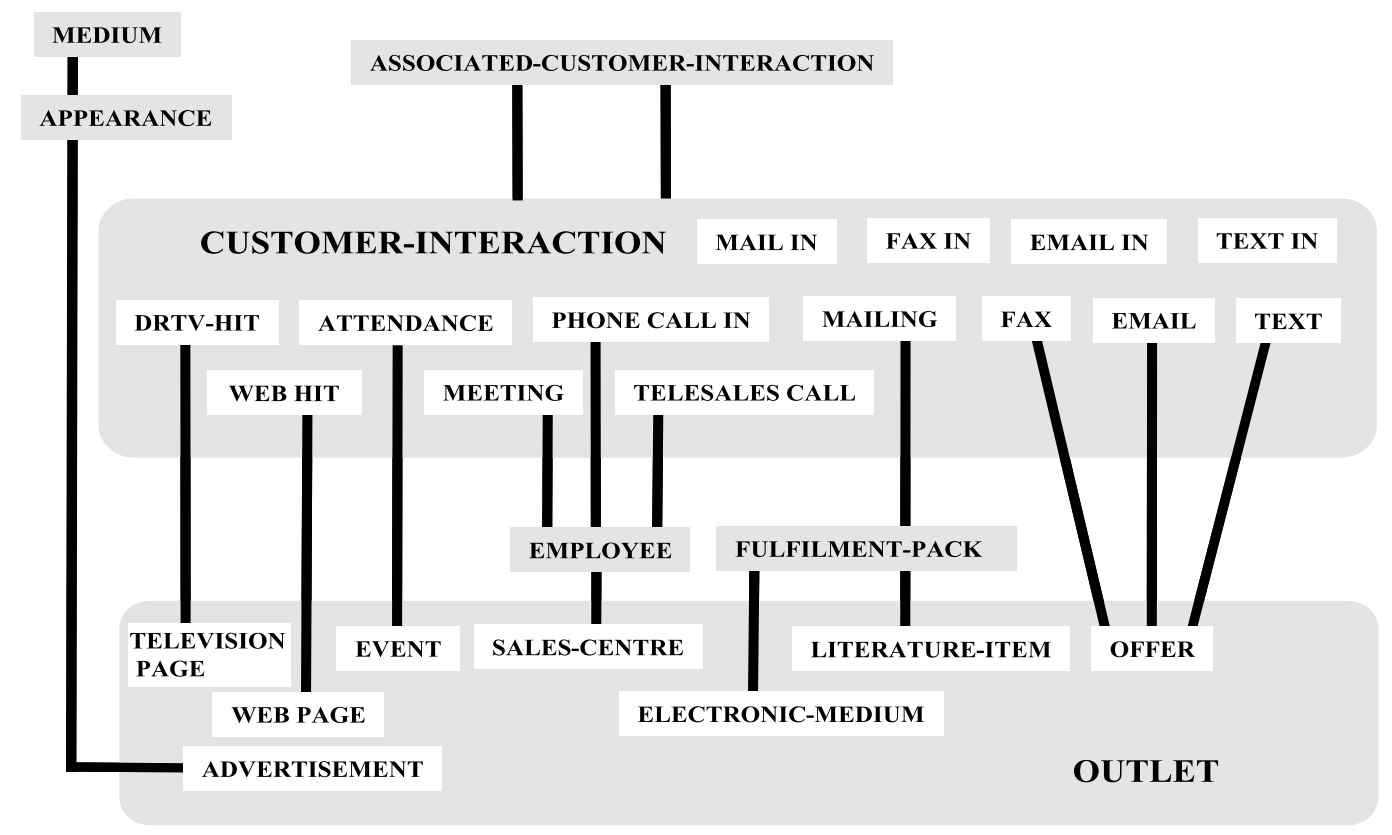

Figure 3: The expansion of the outlet and customer-interaction tables

and the product. The product offer is the record of which product or service has been offered, in which outlet and for what time period. The final relationship is the most complex. This is the customer interaction, a record of all communications between company and customer. This is where all sales, marketing and service communications must be recorded. Figure 3 shows how this relationship can be expanded: the outlet table is also shown, as the type of interaction varies according to the outlet. Note that this diagram is not exhaustive.

Obviously, the database will have more tables, covering addresses, statements, payments and campaigns, as well as other customer information such as demography and lifestyle and perhaps satisfaction and preferences questionnaire data. In each sector, there will be data (particularly that which provides insight into customer value and profitability) and look-up tables that are industry specific. More than 90 per cent of all data — in some cases 99 per cent — will be held in the six groupings shown in grey blocks within
Figure 3. Too many customer management systems suffer from overdesign and so are very hard to build, even harder to maintain and, much worse, impossible for the user to understand. If users (usually in sales and marketing) cannot understand the overall picture and common language, they cannot fully engage and use the information effectively. Using these table groups, it is possible to calculate all income accruing to the business from sales of products and services to customers. It is also possible to overlay all direct and indirect costs, with a high degree of accuracy in apportionment. This means that true net profitability can be calculated for each of the three original tables: product, outlet and customer. ${ }^{3}$

\section{Analysis plan}

It used to be thought that analysis planning could be left until the last stages of data planning. So much of the usefulness of customer data depends, however, on how they are analysed, that 
Table 1: Problems in customer data planning

\begin{tabular}{ll}
\hline Problem area & Outcome \\
\hline $\begin{array}{l}\text { Control } \\
\text { ROI on data management } \\
\text { projects }\end{array}$ & $\begin{array}{c}\text { Limited control over too many legacy systems } \\
\text { Inability to pull together a single view of the customer for analytics and/or } \\
\text { operations } \\
\text { Inability to justify the return on investment (ROI) from staged data quality } \\
\text { assessment and improvement projects, since payback is not easily } \\
\text { quantifiable, particularly in its impact on revenue and profitability } \\
\text { Weak sponsorship or support from rest of customer management } \\
\text { programme delivery } \\
\text { Failure to deliver CRM improvements to specification during the previous } \\
\text { year } \\
\text { No agreement among marketing, sales and customer service teams on } \\
\text { common approach to CRM } \\
\text { Improvement is local and tactical rather than replicated, integrated or } \\
\text { strategic } \\
\text { Lack of access to the internal or external skill sets needed to improve CRM } \\
\text { implementation and ROI achievement }\end{array}$ \\
Skills &
\end{tabular}

it should be one of the first areas to plan and, at least partially, implement.

Decisions are required to determine which data are collected and analysed ${ }^{4}$ in order to develop the required propositions from market and customer knowledge and to measure the effectiveness of operational customer management activities against objectives.

\section{PROBLEMS IN CUSTOMER DATA PLANNING}

The main problems in customer data planning are summarised in Table 1.

\section{IMPLEMENTING A CUSTOMER DATA PLAN}

\section{Creating an enterprise customer information management plan}

The production of a comprehensive customer information plan can be difficult. This is shown by how few organisations claim to have such a plan in place. In over 500 assessments using QCi's Customer Management Assessment Tool, only 4 per cent claimed to have a comprehensive customer information plan. Such a plan requires input and agreement on a wide range of complex issues across different functional groups - all of which will typically come to the table with different, and even conflicting, priorities. Added complexity comes from the rate of change in the capabilities available in support of information management and usage, and the mid to long-term time horizon on which such plans will typically deliver.

\section{Obtaining resources to support the plan}

Customer information management and usage, by its nature, includes a range of skill sets which are in short supply. So organisations must ensure that they have sufficient resources in place to meet current business needs and that succession planning and growth in line with business needs is also taken into account.

\section{Building measures of data quality}

Organisations should understand and measure the impact of data quality on the range of customer management processes and build business cases for data quality improvement programmes. These measures should include, for example, financial data on wasted marketing and 
Foss et al.

sales activity generated by poor data inputs.

\section{Defining a single customer view}

This definition should set out an aspiration and a high-level plan and timeline for putting this view in place, but should also be informed by a realistic view of the costs and benefits to be had by implementing this view. When does it need to be an analytic or a real-time view; need it initially be the only customer record or other key data too? Possibly, but each organisation must work through the issues specific to their sector, type and size of customer base, existing infrastructure, business case and priorities.

\section{Collecting transaction histories, deriving customer value from them and using value information}

Data held at the lowest level (typically transaction level) are needed as a basis for analysis, planning, customer management activity and measurement. Organisations should try to hold at least three years of data at transaction level, appended to each customer identifier, including date, product, volume, channel/outlet and margin of each transaction. To decide whether acquiring, serving, developing and keeping particular customers is worthwhile, their present and likely future value must be estimated. Data on value must be made available at the point of contact with the customer so that different actions can be taken depending on customer value.

\section{Privacy}

Care must be taken to observe privacy laws and expectations in storing and using data.

\section{Accounting for third party data (intermediation)}

It is necessary to work with intermediaries to resolve issues, and to be aware of where the business could become an intermediary itself using the data it has, or who could intermediate between the business and its customers.

\section{Outsourcing business processes}

While not advocating outsourcing per se, it is suggested that organisations understand which of their business processes are 'core' (ie which deliver competitive advantage) and which, while critical to business success, could readily be outsourced to a specialist - or where fixed cost structures could be usefully transferred to on-demand variable costs. The management of large customer databases and their integration into business processes requires substantial investment. Specialist companies that support this area can provide broadly the same solution either in-house or out-house. So as well as the core/critical debate, organisations are increasingly drawn one way or another by their preferred approach to investment (eg in-house is likely to be on-balance sheet and outsourced can be off-balance sheet).

\section{Using the customer data to improve the customer interface(s)}

Customer data integration (CDI) technologies now make it feasible to recognise and welcome customers at almost any point of contact. It is also possible in real-time to extract, combine and analyse data pertinent to that customer for true personalisation. This eliminates the need for some data entry and provides the opportunity for validation - both of which can pay handsomely in terms of customer perception and data quality. 


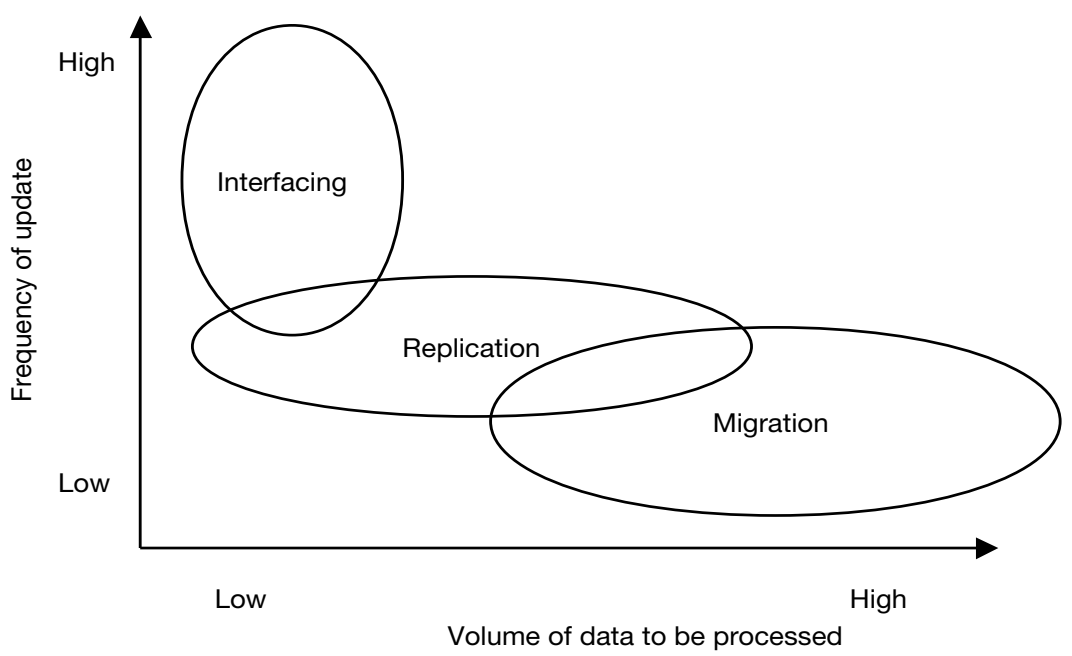

Figure 4: Data movement - timing and volume

\section{Gathering and using customer preference and behavioural data to build customer satisfaction and reduce operating costs}

Some organisations are gathering and using customer preference and behavioural data in areas such as communications (timings, frequencies, channels and content), and also in operational areas such as delivery. When implemented across the enterprise, preference and behavioural data can be a powerful retention driver/barrier to customer exit and a significant contributor to reduced operating costs. Exploiting this capability can also defend against new market entrants that start with limited market knowledge, although they are likely to import good customer and data management practices from elsewhere which may enable them to learn quickly from the preference and behavioural data they collect. If gathered, preference and behavioural data should be used - ignoring them is worse than not gathering them at all.

\section{Ensuring that retention activity is driven by all valid data available}

Very few organisations capture 'reason for loss of customer or product' data and few have a formal win-back programme informed through capturing, combining and analysing all customer history.

\section{Moving and integrating customer data}

For the majority of companies, an important component of their customer data planning and management will be the movement of data between systems to be in the right place at the right time to make a difference to the prioritised development and deployment of customer management capabilities.

\section{Data movement}

Data interfaces, data replication and data migration all share common

characteristics:

- volume of data

— timeliness of movement and processing

- direction of flow (between sources and targets).

A common core of software may be able to manage all these factors, in a scaleable fashion, but certain factors peculiar to each company must also be taken into 
Foss et al.

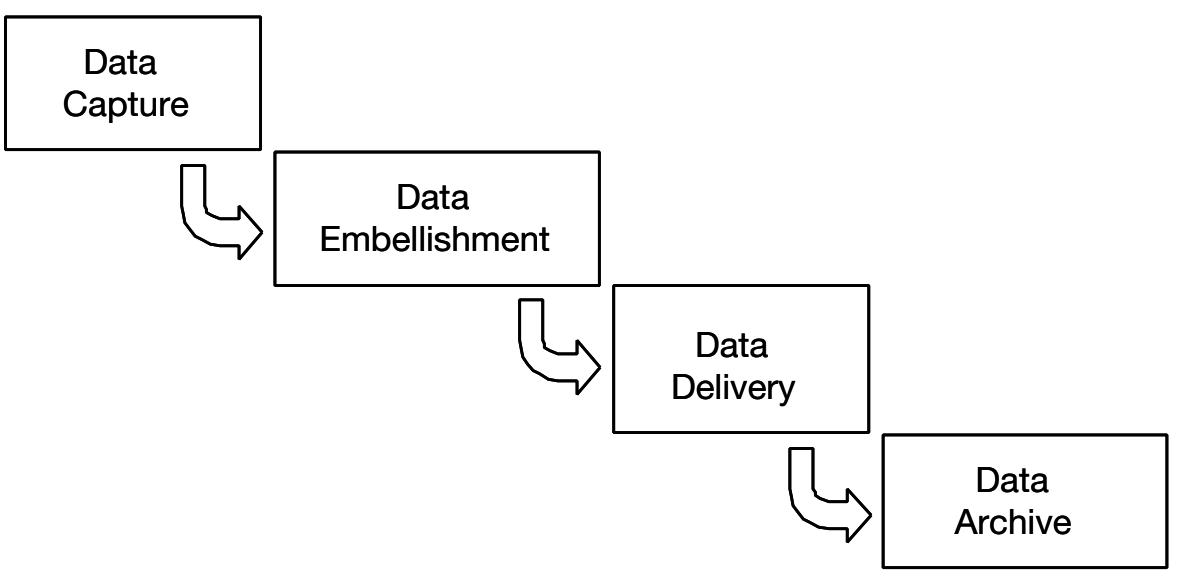

Figure 5: Data flow

account. The software packages that perform well across these areas each have strengths in combining the functions required, such as synchronous and asynchronous messaging, ability to interpret logs and journals, or complex, high-performance data transformation routines to produce a more efficient, manageable and reusable data management capability.

\section{Data flow}

The flow of data within a unit (system, program, enterprise) typically follows the sequence shown in Figure 5.

Data are first captured for use, automatically or manually, irrespective of the quality. The data are then embellished at various times, ie they are added to, but not necessarily enhanced. An audience awaits the data, either in terms of a feed to other systems, or through a presentation layer to users. Finally, data are kept, sometimes indefinitely, sometimes for legal reasons, but also because there will be some value locked into the data. Companies are realising that instead of archiving data offline, the creation of data warehouses using these historical data gives them ability to perform trend analysis and strategic planning.

\section{Data, metadata and reality}

It is insufficient to compare data with their definitions, although this can be an important stage of data assessment and profiling. Stored data should also be compared with reality. For example, a customer name and address may be stored, but if the customer has moved since the data were entered, neither the stored data nor the metadata give a reliable business basis on which to proceed. The IT industry tends to be parochial in its treatment of data and focuses on the mechanics of data storage and data transportation. The importance of comparing data against real-world facts, however, tends to fall between business and IT responsibilities, both claiming there is insufficient time and resource for the task. When this happens, data quality levels are usually low and business opportunity losses due to poor data quality are accepted as 'normal'.

\section{Data accuracy and integrity}

Comparison between data and appropriately descriptive metadata can provide some basic checking, such as value ranges, and data type. Statistical techniques can also be applied to gain further insights into valid and invalid 


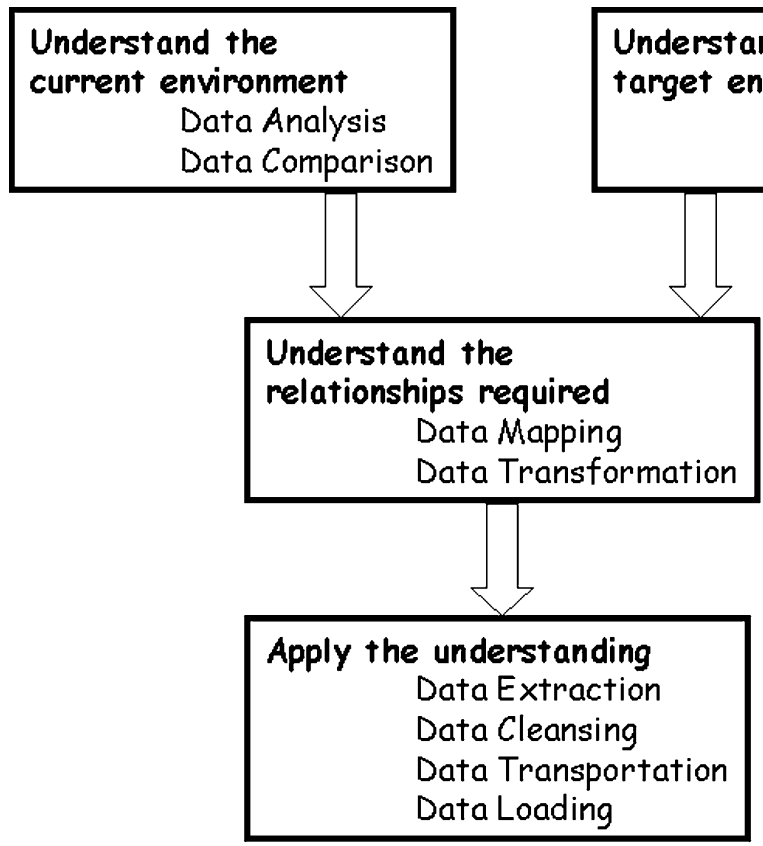

Figure 6: Approach to planning data migration

distributions of data content. Relational database management system technology permits a strict relationship between data and their physical data definitions, but where file-based systems are still in use and maintenance is frequent, metadata can get out of step with the actual data over time. Where multiple values occur, candidate items must be compared against some standard, or scored and weighted appropriately. This process must include a method for cross-referencing between data items or systems, and a tracking function to indicate where these values are now superseded by a 'master' value.

Part of accuracy is precision. A streaming video could be accurate (in that it shows moving images which can be interpreted correctly by the viewer) but still lose bits or whole frames. Losing one or more zeroes from a financial transaction would affect the accuracy of the value, while limited data losses in customer management may be acceptable, allowing early CM actions to be undertaken with imperfect (but understood) data quality limitations. Precision is therefore relative and data precision objectives and efforts must be appropriate to business use and cost/benefit cases.

Integrity can be applied to logical business entities but, within a migration or movement context, it refers to the referential integrity of relational database management systems. This enables key relationships to be rigorously maintained, and includes other data constraints such as null values, exclusivity, etc. Measuring the 'integrity' of data means ensuring that relationships between data items are valid.

\section{TAKING THE FIRST STEPS}

For companies to progress they must understand the health and relevance of their data and systems. The process is summarised in Figure 6.

\section{Migration options}

Most data are simple, in that they are stored as easily readable text, dates and 
numbers. Gartner Group ${ }^{5}$ identified three high-level options for migration:

- conversion by function

- conversion by line of business

- direct conversion (big bang).

There are lower-level options. Each company has a unique environment, which may take advantage of some of these lower-level groupings:

- timeboxing: where companies have time or cost constraints on the amount of effort that can be expended, a timeboxed or staged solution, in line with DSDM techniques could be useful

- trickle feed: migrate low volatility base and reference data, but only populate the target with new data, possibly through call centres, e-business or similar data capture points

- analysis only: there will be some value in analysing how a particular business function is implemented across all products or services, so that uniqueness and duplication of information can be measured prior to any corrective work

- guru systems: there are systems where the knowledge of how they work and the responsibility for their maintenance is contained within a very small number of staff. The risk to the company if a key individual is incapacitated may be great, and could by itself warrant a migration

— testing effort: By using packages, companies may want to take advantage of new functionality, such as the ability to cross-sell, or provide complex loyalty arrangements. These functions will require significant testing effort, especially where monetary values are involved, and the time taken to develop and execute test plans may be significant.

\section{Integration options}

Data integration combines data sources through data analysis and data cleansing, to provide a smaller, cleaner, non-redundant data store, for access by multiple applications/packages. This will incur development effort in redirecting interfaces to a new data source.

Application integration consolidates application functionality, either through the re-use of application code, or implementation of package solutions, to provide single functional use with continuous and synchronised update of data across many products and services. This also incurs development effort in re-directing or re-forming interfaces from data sources to new application.

The message integration approach intercepts transactions between systems, and manages them to deliver messages to the correct targets. Application changes are necessary to introduce message handling, but applications and data can be 'loosely-coupled'.

Although environment integration appears to be an effect of migration, it may be a strong reason for migrating data, depending upon the costs associated with maintenance or location of computing resources.

\section{Implementation choices}

The first such choice is between point-to-point and hub and spoke. Point-to-point migrations can meet tactical requirements for data movement, and may be valid if the relationship between source and target is fixed, critical and unique. A more flexible approach would be to introduce a common area to the processing of data between nodes, as there should be some re-use of the functions used (eg date checking, value ranges, EBCDIC to ASCII conversion).

The second choice is between 


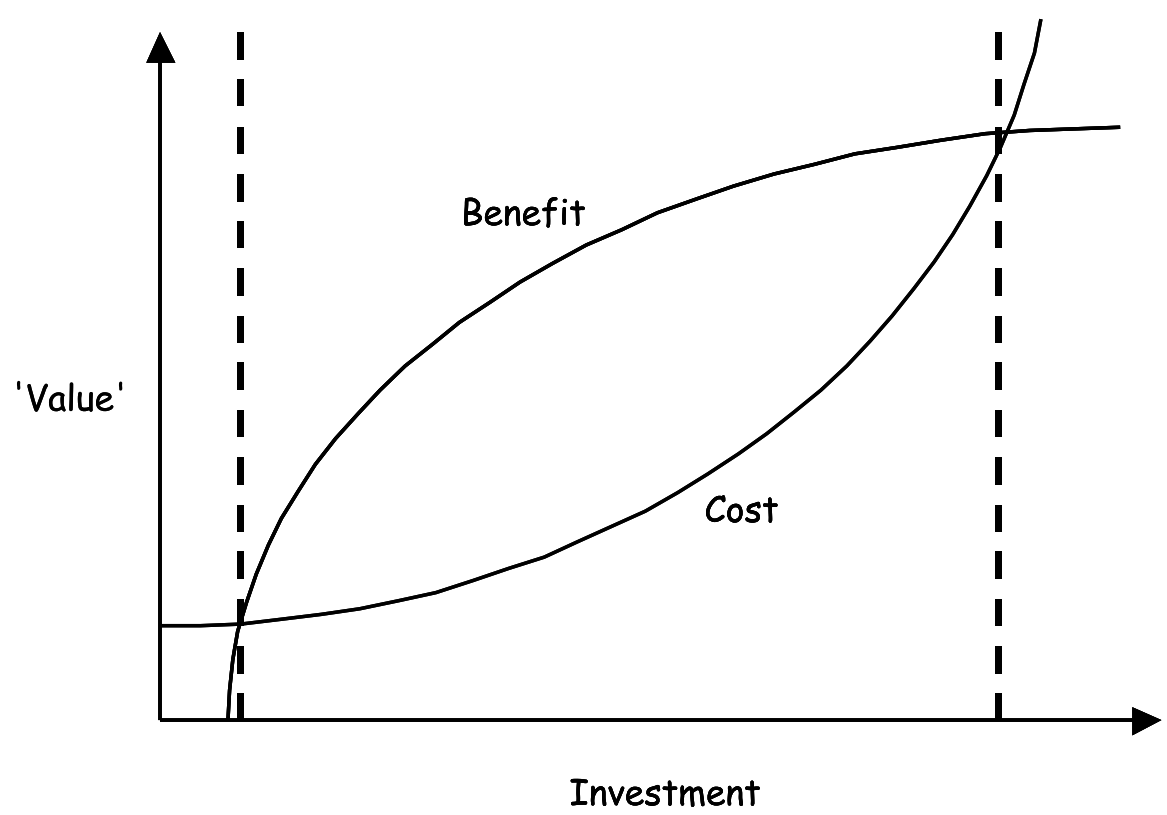

Figure 7: Cost benefits or investment into data quality improvement

development projects and business as usual. Tools can be used to accelerate migration projects and guarantee a higher quality of data to be delivered faster. Company infrastructures are not, however, designed to handle the peak loads normally present in substantial data migrations. There will be contention for resources (batch windows, key staff, etc), as the business must continue to operate while these changes take place. The tools needed to analyse, cleanse, transform and transport data are not necessarily those used to move and transport data operationally.

\section{The main dependencies}

Some migration projects fail because the desired end-state has not been investigated in enough detail to enable successive steps to populate the target successfully. Added to that, there is a natural propensity to spend too long on 'interesting' data that may not have a high value, or spend time honing easily identifiable data such as job titles and telephone numbers.

\section{Planning for data movement - key questions}

To plan for data movement and integration, the questions in Table 2 must be answered.

\section{How much does it cost?}

Expenditure on data quality and data movement should be limited by value to the business. Using business analysis and data sampling methods, the likely costs and benefits of resolving data quality problems can be estimated. This information should enable executives and sponsors to decide where to invest. Although many sophisticated packages have become de facto standards, promising to solve the data quality problem either as their main or subsidiary objective, none appear to satisfy all corporate needs. It may, however, take a long time and large budgets to integrate yet another 
Foss et al.

Table 2: Planning questions

\begin{tabular}{|c|c|}
\hline Business drivers & $\begin{array}{l}\text { What are the main reasons for focusing on integration? eg } \\
\text { - Mergers \& acquisitions } \\
\text { - Divestitures and joint ventures, value chain development, intermediation or } \\
\text { dis-intermediation } \\
\text { - Package implementation (application integration), new channel development and } \\
\text { deployment } \\
\text { - Business Intelligence/Data warehousing/Closed loop operations } \\
\text { - Adherence to legislation (source-to-source migration) } \\
\text { Rightsizing (decommissioning and cost savings), process } \\
\text { transformation/improvements }\end{array}$ \\
\hline People & $\begin{array}{l}\text { What are the skills levels of staff/consultants in interpreting the business meaning of } \\
\text { the data, or providing expert skills in the use of ETL, messaging, analysis and } \\
\text { cleansing software? }\end{array}$ \\
\hline Timescales & $\begin{array}{l}\text { What are the business dependencies upon the new environment, and how is the } \\
\text { business impacted by failure to meet deadlines or quality of data delivered? }\end{array}$ \\
\hline Costs & $\begin{array}{l}\text { What are the initial set-up cost, and running costs of data movement software and } \\
\text { services? What cost model does the customer want to implement? }\end{array}$ \\
\hline $\begin{array}{l}\text { Pollutants and data } \\
\text { quality }\end{array}$ & $\begin{array}{l}\text { Where do data quality problems appear, and what actions are necessary to maintain } \\
\text { quality and avoid re-pollution of data? }\end{array}$ \\
\hline Tactical and strategic & $\begin{array}{l}\text { What quick wins can be gained, and how will a strategy be achieved in stages. } \\
\text { Should point-to-point migration be performed, even though hub-and-spoke } \\
\text { would be more flexible? }\end{array}$ \\
\hline
\end{tabular}

system. If a less functionally rich option were taken from existing packages, would the company achieve a faster ROI and a competitive advantage, or does the competitive advantage only arrive with the implementation of new functionality?

\section{Discipline required}

If there is no visible data architecture, or principles for implementing data into the environment, then data quality will remain low. A data and systems architecture is needed to guide all projects. A set of guiding principles is required, covering:

- policies and procedures, eg all data unambiguously defined, all data are owned by a business area, data are either master or slave

- data characteristics: volatility, content, structure, definition

- data management: monitoring, moving, storage, manipulation.

A quality management approach can be used to manage data migration projects.
There are problems in using such an approach, as they require changes to employees' habits and working practices and most people do not like imposed changes. This may result in hesitation, inertia and a decline in performance. Strong leadership is needed, to pull people and process together, supported by new objectives, measures and rewards.

\section{WHAT DOES THE FUTURE HOLD?}

\section{Data as components}

Re-use of components is becoming essential in delivering accurate data. XML standards have completed the jigsaw for the integration of many e-business applications and their components. De facto standards have emerged since the introduction of the Internet and World Wide Web in that TCP/IP now acts as a standard for communication between nodes, JAVA is a transportable programming and execution environment, and HTML provides a consistent means for publishing data for browsers. XML 
provides another major component, enabling data to carry their definition with them. The UNICODE format for storing data is gaining popularity as both JAVA and XML default to this. Other initiatives such as SOAP and UDDI enable companies to tap into shareable, external stores of high-quality data.

\section{In an ideal world}

A single package and data store may work for smaller businesses but corporate customers need to establish operating rules if enterprise-wide computing is to be implemented. The complexity of business processes and the spread of staff across regions may create problems because:

- different natural languages are spoken. Although a principle could be set that all reporting should be performed in, say, English, local users will invariably have an operating system aligned to the language they speak. This will affect the interface they have with a package

- a single package may provide the functionality for a whole company but competition is fierce in the major functional areas of CRM, ERP and supply chain management. Companies may choose 'best of breed' packages for each function, but the integration of these packages brings with it the complexity of integration, through an application layer rather than a data one

- master/slave relationships must exist between data sets across the enterprise to ensure consistency of information. It may be necessary to store local, regional and global sets of data, which (for performance or security reasons) requires some synchronisation

- legislation within and between countries, such as tax laws and privacy, will require that data be stored or handled in ways that do not suit some packages

- while local issues may require customisation of approach, reuse benefits can be achieved within and across companies and geographies, provided a data architecture and common data management processes and tools are in place.

\section{The market}

As companies rely more on partnership relationships, dependence on information transfer becomes more critical. The advent of enterprise-wide computing has highlighted the many internal customer/supplier relationships that exist between staff and departments. In many companies data quality stands or falls by the ability of the company and its suppliers to ensure that the different software elements used to manage different enterprise-wide applications work together.

\section{SUMMARY}

One hundred per cent accuracy and integrity are rarely achievable. The world is simply too complex. For larger companies the answer may lie in the reuse of real-time data integration suites that are now more readily available from services and tools suppliers. Data complexity is, however, sometimes caused by process complexity. Rather than focusing on data integration, it may be better for a company to focus on process simplification, including introducing straight-through processing. In most companies people own, manage and monitor the data and use them to manage customers. These people must be motivated to manage data well and be supported by senior management, to enable them to work with authority, 
Foss et al.

accountability and responsibility. Human resource management, methods and processes, software and the guiding principles of data management should be combined to provide efficient data management and movement capability.

\section{References}

1 Nelson, S. and Kirkby, J. (2001) 'Seven key reasons why CRM fails', Gartner, 20th August.

2 For more on this see Woodcock, N., Stone, M. and Foss, B. (2002) 'The customer management scorecard', Kogan Page, especially Chapters 9 and 13.
3 For a more comprehensive discussion of customer data architecture, see Foss, B., Devonport, C. and McDaid, P. (2002) 'Achieving ROI from

e-business systems in financial services', in Foss, B. and Stone, M. (eds) 'CRM in financial services', Kogan Page; Foss, B. and Stone, M. (2001) 'Integrating customer management systems', in Foss, B. and Stone, M. (eds) 'Successful CRM', Kogan Page; and Foss, B., Gorchs, T., Uhl, J., Verma, D., Richie, J. and Stone, M. (2002) 'Applying IT in customer management', in Woodcock et al. (2002) op. cit.

4 For more on this, see Foss, B. and Stone, M. (2001) 'Successful CRM', Kogan Page, chapters 3 and 5 .

5 Gartner Group RAS Services (1998) 'Data conversion: What is your risk threshold?', SPA-04-0131. 